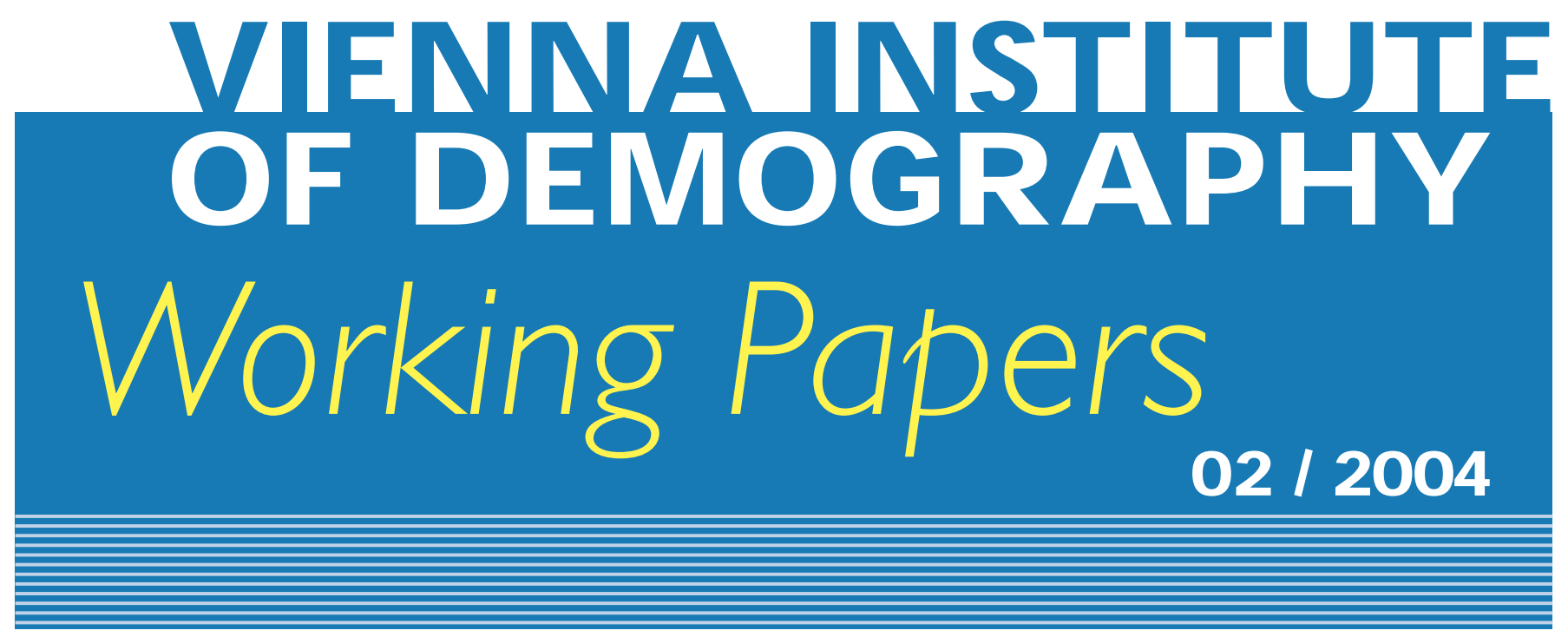

Henriette Engelhardt

\title{
Fertility Intentions and Preferences: Effects of Structural and Financial Incentives and Constraints in Austria
}

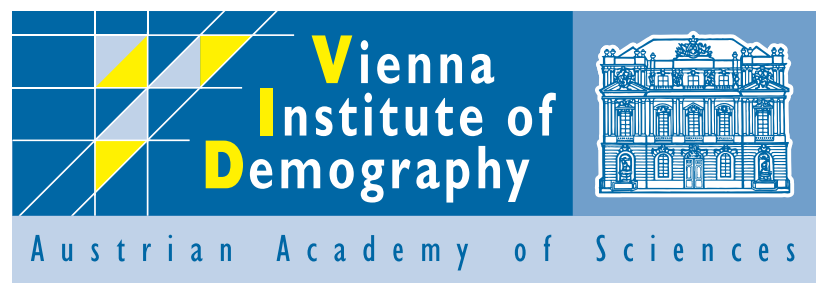

Vienna Institute of D emography Austrian A cademy of Sciences

Prinz Eugen-Strasse 8-10 · A-1040 Vienna · Austria

E-Mail: vid@ oeaw.ac.at

W ebsite: www.oeaw.ac.at/vid 


\title{
Fertility Intentions and Preferences: Effects of Structural and Financial Incentives and Constraints in Austria*
}

\author{
Henriette Engelhardt ${ }^{\dagger}$
}

September 22, 2004

\begin{abstract}
Taking as a starting point the low period fertility rates in Austria, this paper addresses the question to which extent the low period fertility rates in Austria can be accounted for by effects of structural and financial measures. Using data from the Austrian Population Policy Acceptance Survey 2001 we analyse the effects of these two publicly controversial discussed incentives on the desired total number of children, on wanting no (more) children, and on fertility aspirations under the implementation of certain public policies. Based on zero-inflated Poisson models we find that only structural constraints have an effect on the desired number of children, while financial constraints have no effect. Logistic regression results suggest that neither structural nor financial factors affect the desire for wanting (more) children. Concerning the fertility aspiration under the implementation of certain policy measures our results based on matching methods indicate that both structural and financial incentives would have an effect on thinking about having a(nother) child, on deciding to have a(nother) child, as well as on having the first/next child sooner. However, at parity zero financial incentives seemed to be more important, while at parity one especially structural incentives are the driven force of fertility aspirations.
\end{abstract}

\section{Introduction}

In the last several decades, Austria, like most European countries, has experienced severe changes in fertility. In Austria the total period fertility rate dropped from 2.69 in 1960 to 1.39 in 2000 (U.N. Demographic Yearbook 2002).

Understanding what underlies this changing fertility pattern is a central question in population studies. Bongaarts' (2001, 2002) conceptual framework views the total fertility rate as resulting from the population's intended family size mitigated by a set of factors that reflect unanticipated effects, including competing preferences for a career, marital disruption, celibacy and infecundity, unwanted fertility, gender preferences for children, and postponement effects. Thus, both the above factors and declining family size preferences will influence the levels of fertility (Goldstein et al. 2003).

A comparison of the desired number of children with the completed fertility for various European countries indeed shows that actual cohort fertility falls well short of women's reported preferences (Bongaarts 2002). This finding suggests that efforts to help women overcome the various obstacles to the implementation of their preferences would lead to higher fertility (Bongaarts 2001).

\footnotetext{
*I wish to thank Alexia Prskawetz and Maria Winkler-Dworak for helpful discussions.

$\dagger$ Vienna Institute of Demography, Austrian Academy of Sciences, Prinz Eugen-Str. 8, A - 1040 Vienna, Austria, email henriette.engelhardt@oeaw.ac.at.
} 
Figure 1: Observed and desired mean number of children of Austrian women born from 1910-1980

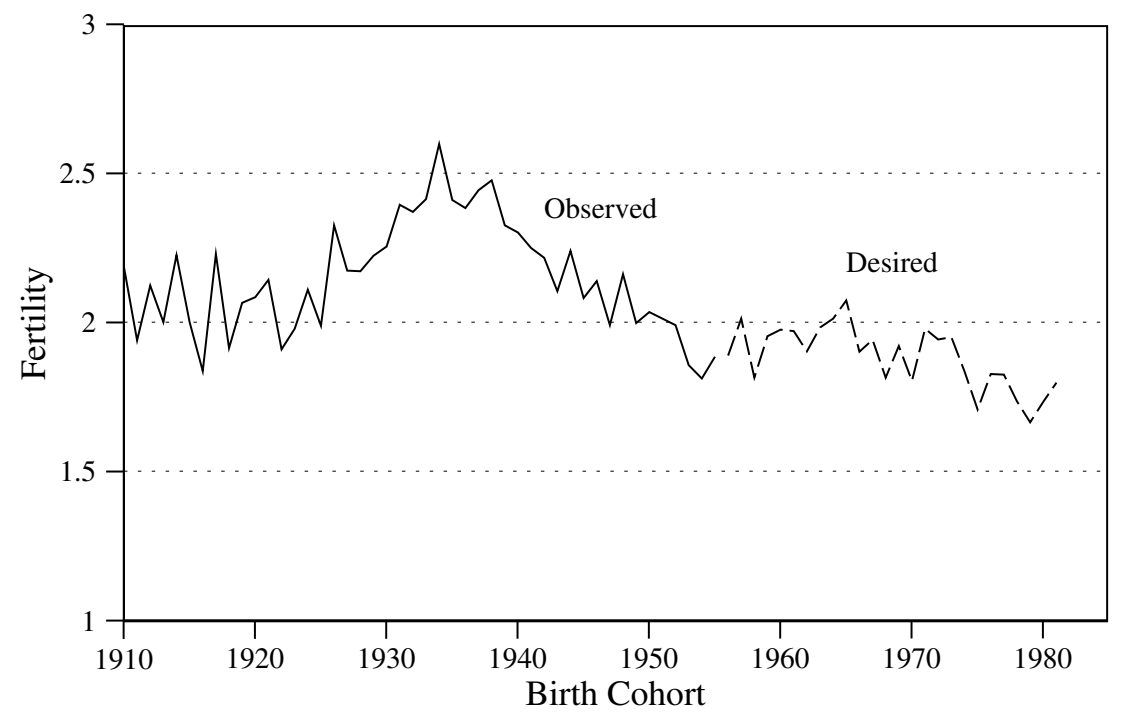

Source: Micro-census 2001, the author's own calculations.

Figure 2: Probability of having a(nother) child, by current parity, for Austrian women born from 1925-1950

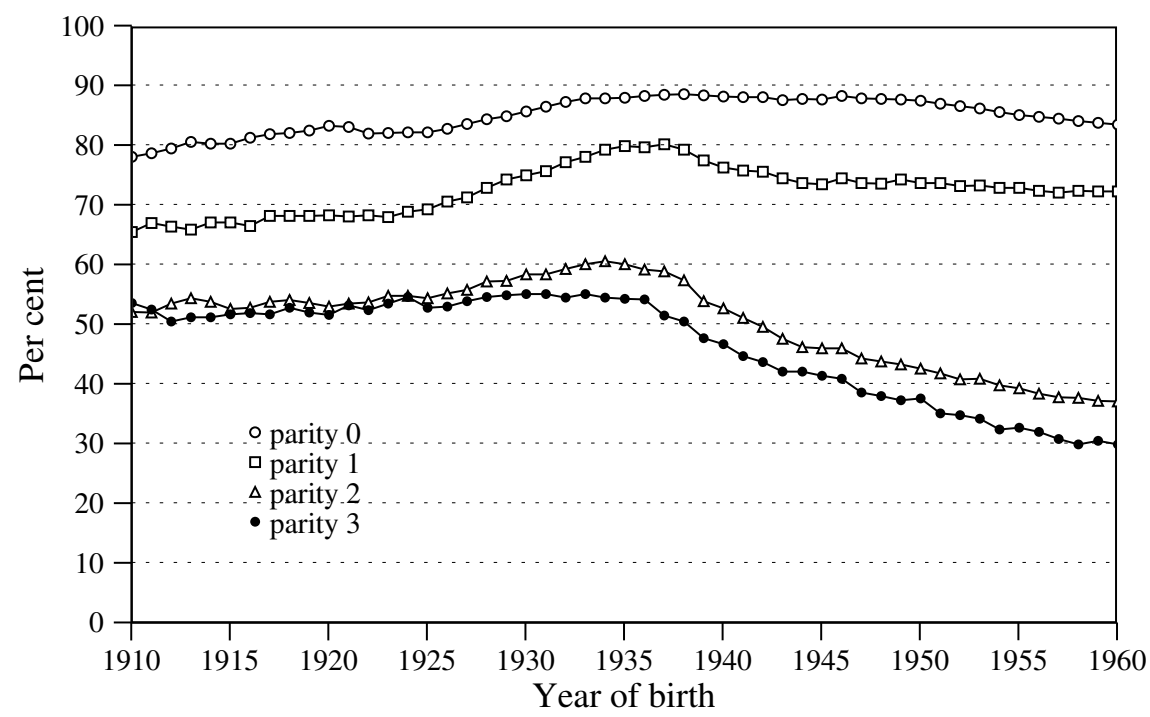

Source: Hanika (2003). 
Figure 1 presents the level of completed fertility for the birth cohorts of Austrian women from 1910 to 1954, together with estimates of the average desired number of children for the cohorts 1955 to 1980 based on the 2001 Austrian micro-census. Ideal family size declined from approximately 2.0 children for the 1960 birth cohort to about 1.7 children for the 1980 birth cohort. The decline in family size preferences for younger reproductive cohorts is very closely correlated with the dramatic decline in completed cohort fertility of the older cohorts.

Moreover, cohort parity progression ratios (Figure 2) provided by Hanika (2003) suggest that much of the actual fertility decline has been concentrated at parities two and above, which means that Austrians have had falling rates for third and higher-order births. ${ }^{1}$ This development can also be considered as evidence for declining fertility preferences at higher parities.

The developments presented in Figure 1 and Figure 2 raise three substantive questions that we attempt to address in this paper: (1) Given the current controversial political debate on structural vs. financial incentives and constraints to increase fertility, which measures have actually a causal effect on fertility intentions and preferences? (2) Are the effects of structural and financial incentives and constraints on fertility intentions and preferences parity specific? (3) Are there differences in the effects for fertility intentions and for family size preferences? (4) Given the hypothetical implementation of certain public policies aimed at improving structural and financial conditions of child bearing and child rearing: Would this work as an incentive for thinking about having children?

Using data from the second Austrian Population Policy Acceptance Survey 2001 (PPA2), we conduct multivariate analysis to estimate the impact of structural and financial incentives and constraints on desired family size and fertility aspirations. Since 1990, the PPA project has been headed and co-ordinated by the United Nations Economic Commission for Europe (UNECE), the Netherlands Interdisciplinary Demographic Institute (NIDI), and the Institute of Population Research (IRP) in Rome, Italy (Moors and Palomba 1995). Like the PPA1 that was carried out in 1992/1993, the PPA2 survey is an international project in which thirteen European countries are taking part.

The rest of this paper proceeds as follows. The next section discusses the theoretical and empirical literature on fertility preferences. Section Three describes the data, variables and methods used in the analysis. The fourth section presents the analyses of fertility preferences, and the final section discusses the implication of those analyses.

\section{Background}

\subsection{Theories on Fertility Intentions and Preferences}

Recently, considerable attention has been paid in the demographic literature to subjective preferences, intentions, ideals, and expectations toward fertility. Although they may happen to be quite similar, they are normally not identical. Fertility preferences refer to the desired number of children over the life course whereas fertility intentions are expectation statements with regard to an individual plan for having children. Some authors refer to the latter concept as fertility expectations. Ideal family size describes the existence of a societal norm regarding family size, while expected size describes a personal norm. ${ }^{2}$

\footnotetext{
${ }^{1}$ Parity progression ratios at parities 4 and 5 are very close to those for parity 3 and are therefore not shown in Figure 2.

${ }^{2}$ Previous research based on international fertility surveys has shown differences between ideal, desired, and realised fertility. Research has shown that these variables differ from one another in a predictable manner, i.e. ideal family size $>$ desired family size $>$ achieved family size. While the personal norm is generally situated
} 
In a simple theoretical perspective on the formation of family size preferences, individual preferences are determined early in life and remain constant throughout the reproductive period (cf. Ryder 1973). In this static view, the factors that shape preferences are primarily those related to a person's individual familial background such as the religious belief and the number of siblings.

In a broader dynamic view, preferences may vary over the life cycle and the decision to have a child has to be considered a sequential and conditional process (cf. Lee 1980; Namboodiri 1983; Lesthaege and Surkyn 1988; Miller and Pasta 1995; Van de Kaa 2001). Factors that potentially lead to an adjustment of fertility preferences are individual education and employment histories, as well as family formation and dissolution histories. In this perspective, fertility intentions must be examined at different parities, because conditions and individual plans may change after each new birth.

In a third view, the same factors that predict fertility behaviour predict fertility preferences (Rindfuss et al. 1988; Heiland and Prskawetz 2003). In this view, the desired family size will reflect the individual's actual and perceived constraints on fertility decisions. A way to think about these constraints is presented by family economics (for an overview see Hotz et al. 1997). According to the economic theory of fertility (Willis 1973; Becker and Lewis 1973; Becker 1991) the demand for children is a function of preferences for children and the monetary and opportunity costs of children. The direct monetary costs for food, clothes, housing, and so forth rise not only with changes in the price levels of these goods but also with the demand for what Becker referred to as 'quality' children, a demand which is correlated with family income. The tradeoff between 'quality' and 'quantity' of children is a matter of individual preference. Thus, desired family size reflects the optimal number of children an individual wants to have given the economic situation and competing interests (cf. Heckman et al. 1985; Heckman and Walker 1990). In turn, fertility preferences will depend on income as well as on the opportunity costs and direct costs of having children.

Not only preferences but also intentions have long been viewed as important in behavioural theories, because they synthesise the influence of individual's background and attitudes, and mediate between these characteristics and behaviour (Ajzen and Fishbein 1980; Ajzen 1985). In this perspective, changing fertility intentions are seen as a precursor to changing fertility behaviour (Schoen et al. 1997). ${ }^{3}$

Empirically, intentions and family size preferences have frequently been the object of study in the literature, but these variables have generally been used in connection with attempts to understand the gap between prospective fertility plans and realised fertility (e.g., DaVanzo et al. 2003; Noack and Østby 2002; Quesnel-Vallée and Morgan 2003; Schoen et al. 1999; Symeonidou 2000; Thomson 1997; Thomson et al. 1990; Van Peer 2002). As Bongaarts (2001) has noted, the economic and value theories of fertility described above often assume that couples can routinely implement their preferences or intentions without difficulty, whereas in reality couples in post-transitional societies often fail to fully realise their fertility intentions, thus creating a gap between desired family size and realised fertility.

This shortfall does not, however, alter the reality that desired family size is highly correlated with observed fertility at the individual level (National Research Council 2001), and that this correlation likely derives from a causal relationship between plans and outcomes (Lesthaeghe and Surkyn 1988; Van de Kaa 2001; Kohler 2001). If we accept the economic framework outlined above, this relationship further implies that social, economic and political institutions do not only affect fertility behaviour directly but also partly via their impact on

under the population norm, achieved fertility is still lower than this personal norm (Van Peer 2002).

${ }^{3}$ Lee (1980) has shown, however, that under many conditions changing intentions will lag behind period fertility as a result of compositional effects within the population. 
desired family size.

The respective impact of structural and financial constraints and incentives on fertility preferences and intentions, however, is primarily an empirical question. The effects should last but not least depend on the given institutional settings in a country organizing womens' work- and family-life.

\subsection{Institutional Settings in Austria}

Based on comparative analysis of family policy in industrialised countries during the 20th century, Gauthier (2002) developed a typology of family-policy regimes: ${ }^{4}$ the social-democratic regime, the conservative regime, the southern European regime, and liberal regime. Within this framework, Austria would correspond mainly to the 'conservative' regime, which is characterised by a system of state support for families that tends to vary according to the parents' employment status, and that also tends to be driven by a more traditional view of the gender division of labour. Compared to the other policy regimes, the level of cash support is medium to high. The support of working parents is at a medium level. Moreover, there are relatively long parental and childcare leaves, but more limited childcare facilities. Other countries belonging to this family-policy type are Belgium, France, Germany, Ireland, Luxembourg, and the Netherlands.

More specifically, during the time period under study, social and family policies in Austria were dominated by the traditional male breadwinner model in which women worked fulltime until they had children and returned to part-time work after a longer interruption. Combining work and family was difficult for women due to the lack of public childcare, the non-existence of a private childcare market and the inconvenient school hours and opening times of many day-care institutions. In 1998, only $4 \%$ of children under age three and $68 \%$ aged 3 to mandatory school age were using any formal childcare arrangements (OECD 2001: 144). Moreover, childcare and children's education are not available as tax deductions (O'Donoghue and Sutherland 1999).

Instead of facilitating women's employment opportunities by providing services, the government gave preference to extended leave for childcare, which has allowed mothers to stay at home with their young children. Since December 2001, there has been a generous 36-month leave with cash benefits equal to 14.53 EUR per day for all women (including students and housewives) who earn less than 14,600 EUR per year. This earnings level is usually exceeded by mothers employed full-time with the consequence that they loose the right to these social benefits.

However, before 2004 there was no legal right for women employed full-time who become pregnant to reduce their working hours after the birth. ${ }^{5}$ Generally, part-time jobs are rare in Austria. In 1999, the employment rate of mothers with children under age 6 in two-parent families was about $66 \%$ and for single mothers $76 \%$ (OECD 2001: 135). At the same time, only $29 \%$ of mothers in two-parent families with one partner employed full-time worked fulltime themselves. Further, the incidence of part-time work for the corresponding group of women is low 31\% (OECD 2001: 135).

To sum up, social policy in Austrian is mainly directed towards financial incentives toward fertility and much less to structural incentives to reduce the incompatibility between childrearing and employment. Thus the central question is, whether this strategy could indeed help

\footnotetext{
${ }^{4}$ Gauthier's (2002) definition of family policy encompasses cash and in-kind benefits such as direct cash transfers to families, tax reliefs for families with children, maternity and parental leave, childcare facilities and subsidies, as well as family law.

${ }^{5}$ Since July 2004, women employed in companies with more than 20 employees do have the right to reduce their working time after birth if they have not interrupted their labour contract since three years.
} 
to increase fertility intentions and preferences. To answer this question, we consider both actual structural and financial constraints as well as hypothetical structural and financial incentives.

\section{Data and Methods}

The fieldwork for the PPA2 in Austria was carried out between June and September 2001 with a gross sample of 3,280 Austrians in the agegroup 20 to 65. In order to achieve a sample size sufficient for a detailed analysis of population sub-groups in the smaller provinces, a multistage, stratified, clustered address-random sample was applied. The respondents were interviewed face-to-face by experienced interviewers. Employing this technique, a net sample of 1,995 questionnaires, or $61 \%$ of the gross sample, was attained. After the deduction of neutral non-responses, this corresponds to a response rate of 73 per cent. The resulting data were for the purposes of analysis weighted according to sex, age, employment, city size and federal state. The questionnaire almost entirely incorporates the PPA2 core module on family policy as well as adapted modules on migration, ageing and gender. For more information on the PPA2 including sampling, field work and the questionnaire, see Gisser (2003). Our empirical analyses are based on female respondents ages 20 to 49 .

\subsection{Fertility Preferences, Intentions, and Aspirations}

In the PPA2 survey, three measures of fertility preferences and fertility intentions were collected. One asks about the respondent's desired total fertility or family size, and the other reflects whether the respondent currently wants more children. Moreover, respondents were also asked to answer a hypothetical question on fertility aspirations under the implementation of certain public policies.

The first question, the one on desired total fertility, was not asked directly of all respondents. Only respondents who were certain or rather likely to have a(nother) child or those who were pregnant were asked: "How many children do you want to have altogether?" For those without further fertility plans we took the actually realised number of children (including stepchildren and adopted children) as the desired family size. ${ }^{6}$ This is generally considered most accurate measure and is therefore the principal indicator used in reports on findings from fertility surveys in developed countries (Bongaarts 1999).

To determine whether the respondent wanted to have any additional children (the second measure), the Austrian PPA2 asked: "Do you want to have a(nother) child in the future?" Respondents were asked to answer using a four-point scale whose categories were 'yes, certainly', 'rather likely', 'rather unlikely' and 'no, certainly not'. Those, who answered 'yes, certainly' and 'rather likely' are coded as 'want more children' for this analysis; those who said 'rather unlikely' or 'no, certainly not' were coded as 'don't want more children'. Although there is no reason to believe that responses to this question are biased in terms of no systematic under- or over-reports (DaVanzo et al. 2003), Bongaarts (1990) notes that some error may arise if respondents think the question relates to immediate plans versus ultimate goals (i.e., the woman thinks the question asks if she wants another child in the next year or two or three, as opposed to by the end of her childbearing years).

Finally, respondents were asked on the fertility aspirations under the implementation of certain public policy measures (see below) as follows: "If those measures that you personally

\footnotetext{
${ }^{6}$ Morgan $(1981,1982)$ suggests that respondents who answer "don't know" to questions related to fertility intentions are an important group that should not be discarded. Unfortunately, in the Austrian PPA2 no distinction can be made between "don't know" and missing for other reasons.
} 
Table 1: Means of fertility preferences, intentions and aspirations

\begin{tabular}{|c|c|c|c|c|}
\hline$\overline{\overline{\text { Variable }}}$ & All & Par. 0 & Par. 1 & Par. 2+ \\
\hline Actual number of children & 1.483 & & & \\
\hline Preference: Desired number of children & 2.013 & 1.324 & 1.496 & 2.578 \\
\hline Intention: Want no more children $(0 / 1)$ & 0.685 & 0.309 & 0.639 & 0.897 \\
\hline Aspiration: As many children as I wish $(0 / 1)$ & 0.397 & 0.455 & 0.499 & 0.318 \\
\hline Aspiration: First/next child sooner $(0 / 1)$ & 0.197 & 0.293 & 0.267 & 0.115 \\
\hline Aspiration: Would think about having child $(0 / 1)$ & 0.278 & 0.310 & 0.404 & 0.203 \\
\hline Aspiration: Will probably decide to have child $(0 / 1)$ & 0.243 & 0.287 & 0.399 & 0.144 \\
\hline
\end{tabular}

Nore: Means for dummy variables are the proportions of categories shown (coded 1). Source: PPA2 data, the author's own calculations.

consider desirable were actually introduced, what consequences would this have on your own life? Please tell me for each of the following possibilities whether or not you agree with it. (a) It would be easier for me to have as many children as I wish. (b) It would allow me to have my first/next child sooner. (c) I would then think about having a(nother) child. (d) I would then probably decide to have a(nother) child. (e) I do not want a(nother) child in any case."

As shown in Table 1 the average desired number of children in the sample of women ages 20-49 is exactly at the net reproduction level of 2.01. The standard deviation is above one which indicates substantial differences in the individual's desired number of children. Despite the high variation in the total number of children desired, the number of children that the respondents actually had was almost always lower. This discrepancy is at least partially due to the fact that most of the respondents had not yet completed their reproductive careers. We address this issue in our analysis by performing a multivariate analysis that controls for age of the respondents. Notwithstanding the fact that not all respondents have finished their childbearing, about $69 \%$ of the respondents did not have any further fertility intentions. According to the answers given in the survey, at least some of the discrepancy between fertility preferences and fertility intentions could be reduced by the implementation of certain public policies (see below): $40 \%$ of the respondents believed it would be easier to have as many children as they wish and $28 \%$ would think about having a(nother) child if policy changes were implemented.

\subsection{Incentives, Constraints, and Control Variables}

The desired public policy measures listed in the questionnaire include leave and work arrangements, childcare facilities, financial incentives and infrastructure: "A number of measures are being discussed that the state could introduce in order both to encourage the decision to have children and raise them, and to improve the living conditions of parents and children. Please tell me for each of those measures whether your are very much in favour, rather in favour, rather against it or very much against it." 1 = very much in favour, $5=$ very much against it. (a) Improved maternity regulations for working women who have small children. (b) Comprehensive tax relief for parents with minor dependents. (c) Better daycare facilities (e.g. creches) for children up to three years of age. (d) Better daycare facilities for children between three and six years. (e) Family allowances, the amount of which depends on family income. (f) Higher birth allowances. (g) A considerable increase of family allowances per child and month. (h) Daycare facilities for children before and after school as well as during the school holidays. (i) Flexible working hours for employed parents with small children. (j) More and improved part-time work opportunities for parents with small children. (k) 
Improving the housing situation of families with small children. (l) Extending leave times for the care of sick family members. (m) Allowances to cover the time after expiry of the parental leave allowances for mothers and fathers who gave up their employed activity in order to care for their children even longer. Items for which the respondent was either very much in favour or in favour were coded as 'desired public policy measures'.

In addition to these rather hypothetical questions, the PPA2 also contains information on aspects of the actual structural and financial situation that might affect childbearing and childrearing decisions. The questions on "Are there enough daycare facilities in your neighbourhood?" and "How high is your monthly net household income?" were used to create dummy variables for 'enough public daycare in the neighbourhood' and for various levels of 'household income'. Because we do not assume a linear relation between fertility preferences and intentions and household income, six income categories were used. The descriptive statistics of these actual and hypothesized structural constraints are summarized in panel one and two of Table 2 .

Moreover, in the multivariate analysis we control for individual characteristics such as age, religion (catholic or not), educational attainment (Matura or not), employment status, and size of the town of residence, as well as for marital and partnership information, including the educational attainment and employment status of the partner (cf. Table 2).

\subsection{Count Data and Treatment Effect Models}

When analysing the determinants of the desired number of children in a multivariate model one has to take care of the nature of the dependent variable, which are typical count data. In principle, we could analyse these data using standard multiple linear regression. But the preponderance of zeros $(\mathrm{n}=258)$ and the small values indicate that the dependent variable is clearly discrete nature. The Poisson regression model accounts for these characteristics and has been widely used to study such data. A problem with the standard Poisson model is often that the equidispersion assumption $(E(Y \mid X)=V(Y \mid X)=\lambda)$ is violated, i.e. the conditional mean does not equal the conditional variance. To solve this problem, different approaches have been proposed, including the generalised event count model and the generalised Poisson model to account for overdispersion $(E(Y \mid X)<V(Y \mid X))$ and underdispersion $(E(Y \mid X)>$ $V(Y \mid X)$ ) (Winkelmann 2003). Descriptive statistics for the Austrian PPA2 data indicate strong evidence of underdispersion, i.e. the conditional mean exceeds the conditional variance in the full sample. Therefore, we estimated a zero-inflated Poisson model which accounts for underdispersion and for the prevalence of zero counts in the data (Winkelmann 2003).

In the zero-inflated Poisson model, zero outcomes can arise from one of two regimes. In one regime, the outcome is always zero (e.g. the infertile). In the other, the usual Poisson process is at work, which can produce the zero outcome or some other. Let $c$ denote a binary indicator for regime $1\left(c_{i}=1\right)$ or regime $2\left(c_{i}=0\right)$, and let $y_{i}^{*}$ denote the outcome of the Poisson process in regime 2 . Then the observed count $y_{i}$ is given by:

$$
y_{i}=\left\{\begin{array}{ll}
0 & \text { if } c_{i}=1 \\
y_{i}^{*} & \text { if } c_{i}=0
\end{array} .\right.
$$

If the probability that $c_{i}=1$ is denoted by $\omega_{i}$, the probability function of $y_{i}$ can be written as

$$
P\left(Y_{i}=y_{i} \mid x_{i}\right)=\left\{\begin{array}{lll}
\omega_{i}+\left(1-\omega_{i}\right) e^{-\lambda_{i}}, & \text { if } & y_{i}=0 \\
\left(1-\omega_{i}\right) \frac{\lambda_{i}^{y_{i}} e^{-\lambda_{i}}}{y_{i} !} & \text { if } & y_{i}=1,2, \ldots
\end{array} .\right.
$$

Thus, the probability of zero outcomes equals the probability of belonging to regime $1\left(\omega_{i}\right)$ plus the probability of belonging to regime $2\left(1-\omega_{i}\right)$ times the probability of a zero outcome 
Table 2: Means of structural and financial incentives and constraints and of control variables by parity

\begin{tabular}{|c|c|c|c|c|}
\hline & "All & Par. 0 & Par. 1 & Par. 2+ \\
\hline Policy measure: Maternity regulations (0/1) & 0.891 & 0.927 & 0.912 & 0.862 \\
\hline Policy measure: Flexible working hours $(0 / 1)$ & 0.924 & 0.935 & 0.935 & 0.912 \\
\hline Policy measure: Part-time work $(0 / 1)$ & 0.934 & 0.942 & 0.953 & 0.921 \\
\hline Policy measure: Leave for sick family $(0 / 1)$ & 0.743 & 0.762 & 0.774 & 0.728 \\
\hline Policy measure: Daycare up to age $3(0 / 1)$ & 0.747 & 0.827 & 0.851 & 0.763 \\
\hline Policy measure: Daycare ages 3-6 (0/1) & 0.801 & 0.877 & 0.885 & 0.788 \\
\hline Policy measure: Daycare schoolchildren $(0 / 1)$ & 0.832 & 0.758 & 0.830 & 0.704 \\
\hline Policy measure: Housing situation $(0 / 1)$ & 0.791 & 0.794 & 0.799 & 0.784 \\
\hline Policy measure: Tax relief $(0 / 1)$ & 0.886 & 0.855 & 0.911 & 0.889 \\
\hline Policy measure: Income dependent allowances $(0 / 1)$ & 0.741 & 0.684 & 0.791 & 0.745 \\
\hline Policy measure: Family allowances (0/1) & 0.712 & 0.675 & 0.725 & 0.727 \\
\hline Policy measure: Birth allowances (0/1) & 0.673 & 0.638 & 0.678 & 0.687 \\
\hline Policy measure: Allowances after leave $(0 / 1)$ & 0.791 & 0.776 & 0.769 & 0.807 \\
\hline Enough public childcare in neighbourhood $(0 / 1)$ & 0.537 & 0.358 & 0.479 & 0.658 \\
\hline Household income: up to $1,021.9$ EUR $(0 / 1)$ & 0.109 & 0.154 & 0.141 & 0.072 \\
\hline Household income: 1,022-1,605.9 EUR (0/1) & 0.192 & 0.213 & 0.161 & 0.195 \\
\hline Household income: $1,606-2,189.9$ EUR (0/1) & 0.308 & 0.215 & 0.325 & 0.349 \\
\hline Household income: 2,190-3211.9 EUR (0/1) & 0.264 & 0.252 & 0.249 & 0.277 \\
\hline Household income: $3,212+$ EUR $(0 / 1)$ & 0.127 & 0.167 & 0.123 & 0.107 \\
\hline Age 20-24 (0/1) & 0.122 & 0.361 & 0.109 & 0.008 \\
\hline Age $25-29(0 / 1)$ & 0.166 & 0.286 & 0.218 & 0.079 \\
\hline Age $30-34(0 / 1)$ & 0.206 & 0.147 & 0.215 & 0.233 \\
\hline Age 35-39 (0/1) & 0.189 & 0.081 & 0.190 & 0.241 \\
\hline Age $40-44(0 / 1)$ & 0.167 & 0.071 & 0.124 & 0.236 \\
\hline Age $45-49(0 / 1)$ & 0.150 & 0.054 & 0.143 & 0.203 \\
\hline Single $(0 / 1)$ & 0.295 & 0.800 & 0.267 & 0.046 \\
\hline Married $(0 / 1)$ & 0.598 & 0.150 & 0.649 & 0.805 \\
\hline Separated/divorced $(0 / 1)$ & 0.098 & 0.048 & 0.079 & 0.133 \\
\hline Widowed $(0 / 1)$ & 0.010 & 0.002 & 0.005 & 0.016 \\
\hline Matura $(0 / 1)$ & 0.279 & 0.496 & 0.204 & 0.201 \\
\hline Partner: Matura (0/1) & 0.169 & 0.173 & 0.188 & 0.159 \\
\hline Employed full-time $(0 / 1)$ & 0.368 & 0.606 & 0.298 & 0.279 \\
\hline Employed part-time $(0 / 1)$ & 0.236 & 0.105 & 0.308 & 0.270 \\
\hline Partner: employed full-time $(0 / 1)$ & 0.711 & 0.492 & 0.727 & 0.819 \\
\hline Catholic $(0 / 1)$ & 0.843 & 0.824 & 0.816 & 0.864 \\
\hline$<5.000$ inhabitants $(0 / 1)$ & 0.431 & 0.345 & 0.301 & 0.530 \\
\hline 5.000-49.999 inhabitants $(0 / 1)$ & 0.225 & 0.229 & 0.268 & 0.205 \\
\hline 50.000-999.999 inhabitants $(0 / 1)$ & 0.135 & 0.135 & 0.216 & 0.098 \\
\hline $1.000 .000+$ inhabitants $(0 / 1)$ & 0.210 & 0.291 & 0.215 & 0.167 \\
\hline
\end{tabular}

Note: Means for dummy variables are the proportions of categories shown (coded 1). Source: PPA2 data, the author's own calculations. 
when following the Poisson process $\left(\exp \left\{-\lambda_{i}\right\}\right)$. The probability of outcomes greater than zero is the probability of belonging to regime 2 times the probability from the Poisson process. Hence, the standard Poisson model is nested in the zero-inflated Poisson model for $\omega=0$.

Systematic variation can be introduced in the parameter $\lambda_{i}$, as in a log-linear model:

$$
\lambda_{i}=\exp \left(x_{i}^{\prime} \beta\right)
$$

The coefficients in this model can not be interpreted directly; only the sign of a coefficient indicates the direction of an effect. However, the expected number of events is given by:

$$
\frac{\partial E\left(y_{i} \mid x_{i}\right)}{\partial x_{i}}=\frac{\lambda_{i}}{\left(1+\lambda_{i}\right)^{2}} \beta .
$$

In our analysis, we calculated this marginal effect at the means of the independent variables. The effect can be interpreted as the percent increase in number of events accompanying a one unit increase of the independent variable.

An alternative approach to study the effects of structural and financial constraints on the desired number of children is the multinomial logit model (Greene 2003). In this model we simultaneously estimate the effects of those constraints on the probability of intending zero, one, two or more children. The probabilities are given by:

$$
P\left(Y_{i}=j \mid x_{i}\right)=\frac{e^{\beta_{j}^{\prime} x_{i}}}{1+\sum_{k=1}^{J} e^{\beta_{k}^{\prime} x_{i}}}, \quad j=0,1, \ldots, J, \beta_{0}=0,
$$

where $J$ is the desired number of children. The model implies that we can compute $J$ different log-odds ratios $\ln \left(P_{i j} / P_{i k}\right)=x_{i}^{\prime}\left(\beta_{j}-\beta_{k}\right)=x_{i}^{\prime} \beta_{j}$ if $k=0$ for $J$ different outcomes. Thus, the odds ratios are calculated for each outcome independently of those for the other alternatives. This property is called the independence from irrelevant alternatives (IIA) and follows from an initial assumption that the disturbances are independent and homoscedastic. In our application, Hausman tests indicate that the IIA assumption for each possibly omitted category is not fulfilled. Thus, we refrain from presenting the estimated coefficients from the multinomial logit model for the probability of intending zero, one, and two or more children.

To estimate the causal effect of policy measures on fertility aspirations we adopt a matching approach based on the treatment effects literature following the counterfactual model of causal inference. This approach is based on the intuitively attractive idea of contrasting the outcomes of a treatment group $Y_{1}$ with the outcomes of a 'comparable' control group $Y_{0}$. Differences in the outcomes between the two groups are attributed to the treatment $D$.

Matching methods for estimating causal effects have several advantages. First, they make no assumptions about the functional form of the dependence between the outcome of interest and the control variables $X$. Second, matching ensures that the $X \mathrm{~s}$ of interest in the treatment group are similar to those in the control group and, thus, prevents from comparing units that are dissimilar. Third, since fewer parameters are estimated than in a traditional regression model, matching may be more efficient which can be important with small samples.

The method is based on the identifying assumption that, conditional on $X$, the outcome (here: the fertility aspiration) of the control group $Y_{0}$ is independent of the treatment $D$ (here: the implementation of the desired public policy measure). Using the notation of Dawid (1979), the assumption

$$
Y_{0} \Perp D \mid X,
$$

is sufficient to identify the mean effect of treatment on the treated (Rosenbaum and Rubin 1983):

$$
E\left(Y_{1}-Y_{0} \mid D=1\right)=E\left(Y_{1} \mid D=1\right)-E\left(Y_{0} \mid D=0\right) .
$$


Assumption (6) produces a comparison group that resembles the control group of an experiment in one key aspect: conditional on $X$, the distribution of $Y_{0}$ given $D=1$ is the same as the distribution if $Y_{0}$ given $D=0$ :

$$
E\left(Y_{0} \mid X, D=1\right)=E\left(Y_{0} \mid X, D=0\right)=E\left(Y_{0} \mid X\right) .
$$

For estimating the mean effect of treatment on the treated, many matching estimators have been proposed that exploit (6) or its implication (8) for alternative matching methods. For all matching methods, the average treatment effect for the treated (7) can be written as (Heckman et al. 1998):

$$
E\left(Y_{1}-Y_{0} \mid D=1\right)=\sum_{i \in T} w_{i}\left[Y_{1 i}-\sum_{j \in C} W_{i, j} Y_{0 j}\right],
$$

that is, the average (weighted by $w_{i}$ ) of the differences between the events $Y_{1 i}$ of the treatment group $T$ and the events $Y_{0 j}$ of the control group $C$ weighted by $W_{i, j}$. The different matching algorithms differ in the construction of the comparison weights $W_{i, j}$.

Traditional matching methods pair non-treated with treated persons that are 'close' in terms of $X$ using different metrics, e.g. caliper matching of different widths, Mahlanobis distance matching, or Kernel-based matching. In practice (i.e. with samples of typical size) it is often difficult to match on high dimensional $X$. Recently, attention has focused on matching techniques that compare persons based on their probability of treatment. These techniques are labelled propensity score matching (Rosenbaum and Rubin 1983). Define the probability of treatment or propensity score as

$$
P(X)=P(D=1 \mid X) .
$$

A theorem of Rosenbaum and Rubin (1983) demonstrates that if (6) is satisfied, then

$$
Y_{0} \Perp D \mid P(X)
$$

provided $0<P(X)<1$, so that there is a positive probability that the events $D=1$ and $D=0$ occur. This insight shows that matching can be performed on $P(X)$ alone, provided that $P(X)$ is known. Matching on $P(X)$ reduces a potentially multi-dimensional matching problem to a one-dimensional problem.

Propensity scores are implemented in the matching techniques by (1) defining the closeness of propensity scores and the control variables $X$ in different ways, (2) using different methods and different sets of covariates to estimate propensity scores, (3) matching on key covariates in $X$ and then matching on propensity scores, and (4) matching multiple cases to each treatment case (see Rosenbaum and Rubin 1995; Rubin and Thomas 1996; Smith 1997). In this study, we apply Kernel matching based on the propensity score (Becker and Ichino 2002; Gangl and DiPrete 2004). However, additional analysis with different matching techniques yielded similar results.

\section{Empirical Evidence}

\subsection{Desired Number of Children}

We first consider influences on the desired number of children. First, the family-size preference depends strongly on the actual number of children: For women with no previous births, the 
Table 3: Effects of structural and financial factors on the desired number of children, zeroinflated Poisson regressions (marginal effects) for parity 0,1 , and $2+$

\begin{tabular}{|c|c|c|c|c|}
\hline & All & Par. 0 & Par. 1 & Par. 2+ \\
\hline Enough childcare in neighbourhood & $0.175^{*}$ & -0.030 & 0.042 & 0.033 \\
\hline Household income: 1,022-1,605.9 EUR & -0.007 & -0.095 & -0.102 & 0.140 \\
\hline Household income: 1,606-2,189.9 EUR & 0.058 & -0.100 & 0.087 & 0.222 \\
\hline Household income: 2,190-3,211.9 EUR & 0.135 & 0.001 & 0.086 & 0.131 \\
\hline Household income: $3,212+$ EUR & -0.160 & -0.028 & -0.169 & -0.077 \\
\hline Age $25-29$ & -0.180 & -0.020 & 0.133 & 0.182 \\
\hline Age $30-34$ & -0.318 & $-0.128^{*}$ & -0.250 & 0.261 \\
\hline Age $35-39$ & -0.295 & $-0.241^{* *}$ & $-0.471^{* *}$ & 0.450 \\
\hline Age $40-44$ & $-0.369^{*}$ & $-0.373^{* *}$ & $-0.555^{* *}$ & 0.436 \\
\hline Age $45-49$ & -0.343 & $-1.046^{* * *}$ & $-0.640^{* * *}$ & 0.523 \\
\hline Married & $0.549 * * *$ & 0.023 & 0.083 & -0.210 \\
\hline Separated/Divorced & $1.161^{* * *}$ & -0.173 & 0.274 & 0.265 \\
\hline Widowed & $1.219^{* *}$ & $-0.327^{* * *}$ & $-0.445^{*}$ & 0.034 \\
\hline Matura & 0.146 & $0.089^{*}$ & -0.123 & 0.123 \\
\hline Partner: Matura & -0.055 & -0.026 & -0.059 & 0.000 \\
\hline Employed full-time & $-0.474^{* * *}$ & -0.005 & $-0.397^{* *}$ & -0.235 \\
\hline Employed part-time & $-0.246^{*}$ & -0.018 & $-0.375^{* *}$ & -0.216 \\
\hline Partner: employed full time & 0.049 & 0.042 & $-0.261^{*}$ & -0.025 \\
\hline Catholic & 0.100 & -0.032 & -0.273 & 0.085 \\
\hline 5,000-49,999 inhabitants & $-0.207^{*}$ & 0.021 & -0.180 & -0.178 \\
\hline 50,000-999,999 inhabitants & -0.254 & -0.034 & -0.186 & -0.021 \\
\hline $1,000,000+$ inhabitants & $-0.345^{* *}$ & -0.051 & -0.202 & 0.092 \\
\hline$\overline{\mathrm{N}}$ & 609 & 203 & 122 & 284 \\
\hline McFadden's $R^{2}$ & 0.031 & 0.168 & 0.067 & 0.008 \\
\hline$S$ & 0.251 & 0.424 & 0.293 & 0.216 \\
\hline
\end{tabular}

Notes: ${ }^{* * *} p \leq .001,{ }^{* *} p \leq .01,{ }^{*} p \leq .05$. McFadden's pseudo $R^{2}=1-[\ln L(\alpha, \beta) / \ln L(\alpha)]$, where $\ln L(\alpha, \beta)$ is the $\log$-likelihood value of the full model and $\ln L(\alpha)$ is the log-likelihood value of the constant only model. $S=\exp (\ln L(\alpha, \beta) / n)$ gives the average probability that the model generates the data. Source: PPA2 data, the author's own calculations.

fertility preference is with 1.32 desired children lowest, followed by 1.50 desired children at parity one, and 2.14 children at parity two, and 3.44 children at higher parities. In short, the desired number of children increases with parity.

The marginal effects of the structural and financial determinants on family-size preferences, as well as individual and partner characteristics on the desired number of children from the zero-inflated Poisson model are listed in Table 3. Because the desired number of children was never equal to zero for women at parity one and above, standard Poisson results are listed in columns three and four. The overall goodness-of-fit is good at all parities, but decreases with increasing parity. The best model fit is obtained at parity zero with an average probability of $42.4 \%$ that the model generates the data.

Most interestingly, the distribution and availability of public childcare close by is a statistically significant determinant of the desired number of children. The desired family size increases by $17.5 \%$ in the presence of hypothetically available public childcare. Concerning the financial aspects, the desired number of children decreases for women with increasing household income, however not at a statistically significant level. However, the effect of income seems to be parity specific. At parity one, the effect of household income is inversely U-shaped, that is, women at lower and higher income levels have a lower demand for children. Summing up, only the structural factor has a clear pattern for all parities: provision of public childcare increases the desired number of children for all parities. 
Of course, the total impact of these structural and financial constraints is reflected not only by the size of the coefficients but also on the proportion of women who fall in the respective categories. Table 1 shows differences in the distribution of these two factors. Most interestingly, the actual availability of public childcare increases by parity. While only $36 \%$ of childless women have enough public childcare in their neighbourhoods, almost $66 \%$ of women with two or more children report a sufficient support in terms of public childcare. Concerning the financial constraints, childless women are more often among the lower household income groups and women at higher parities are more often among the higher income groups. However, the actual number of children is inversely U-shaped by household income (not shown in the table). The number of children increases with household income and reaches its maximum in the 1,606-2,190 Euro income group and decreases with higher household income.

Let us have also a look at the effects of the control variables in Table 3. The desired family size decreases with age in the model for all women and is also lower for single women compared to married, separated, divorced and widowed women. For women employed fulltime or part-time the desired family size decreases by $47 \%$ and $25 \%$ respectively compared to non-employed women. Moreover, the desired family size decreases with the number of inhabitants in one city or town of residence. In Vienna (the only Austrian city with more than one million inhabitants), the desired family size is about $35 \%$ lower compared to small villages with fewer than 5,000 inhabitants.

\subsection{Wanting More Children}

Next we consider the proportion of women who do not want a(nother) child by parity. The proportion of women with no further fertility intentions depends strongly on the actual number of children: For women with no previous births, the proportion not wanting a child is about $31 \%$. This fraction increases further to $64 \%$ at parity one, to $89 \%$ at parity two, and finally to $92 \%$ at parity three.

The reasons that women give for not wanting a(nother) child are summarised in Table 4. At parity zero the three most often given reasons are "I would have to give up leisure-time activities", "I want to maintain my current standard of living" and "I would not be able to enjoy life as much as I can now". At parity one, almost half of the women have already had all the children they want, and a third felt that either she or her partner was too old for another child. In addition to these 'neutral drop outs' almost $30 \%$ are "too concerned about the future of my children" and $27 \%$ reported "a(nother) child would cost too much". At higher parities, the women's own leisure time and enjoyment of life take a back seat. Financial aspects and structural restrictions like "my job and professional activities would not allow it" (32\%) and "a(nother) child would cost to much" (35\%) are listed as obstacles for having more children. Most interestingly, these aspects do not seem to be important for women at parity zero.

Unfortunately, the evidence above is only suggestive. It has, however, been used previously to make similar arguments. It has a fundamental weakness, specifically, a severe form of selectivity results from the question format: only those wanting no additional children were asked this set of questions. It is, on the one hand, possible that women who intend to have more children do not experience these subjective obstacles, in which case the information provided by women who do not intend to have more children in fact explains their intentions. On the other hand, it is also possible that women who intend to have more children are as likely to agree that "I would have to give up leisure activities" as are women who do not intend to have children. In this case, this perception is obviously not the cause of their fertility intentions. Because there is no way to know from these data alone how women who 
Table 4: Reasons why Austrian women do not intend to have a(nother) child, by parity

\begin{tabular}{|c|c|c|c|c|}
\hline & A All & Par. 0 & Par.1 & Par. 2+ \\
\hline I already have all the children I want & 57.0 & 1.5 & 47.4 & 82.3 \\
\hline My state of health does not allow it & 21.4 & 7.9 & 23.9 & 30.4 \\
\hline I live alone and don't have a steady partner & 15.7 & 10.4 & 13.0 & 26.4 \\
\hline My job and professional activities would not allow & 20.3 & 8.7 & 17.3 & 32.4 \\
\hline I would have to give up leisure-time activities & 16.0 & 14.4 & 17.7 & 16.4 \\
\hline I want to maintain my current standard of living & 30.4 & 17.5 & 23.2 & 43.2 \\
\hline A(nother) child would cost too much & 25.8 & 11.2 & 26.8 & 34.9 \\
\hline I am too concerned about the future of my children & 31.2 & 12.2 & 29.7 & 44.4 \\
\hline I would not be able to enjoy life as much as now & 19.1 & 16.0 & 22.5 & 19.3 \\
\hline I am too old/my partner is too old & 35.7 & 12.8 & 34.7 & 52.1 \\
\hline My partner does not want a(nother) child & 20.1 & 3.2 & 23.4 & 32.4 \\
\hline
\end{tabular}

Note: All numbers in per cent. Source: PPA2 data, the author's own calculations.

intended to have more children would have answered the questions, it is not possible to draw valid inferences about causation from the subjective obstacle questions alone. Fortunately, we have the information on household income and neighbourhood childcare provision for all women. We are therefore able to determine if structural and/or financial factors discriminate between those who intend and do not intend to have more children.

Table 5 shows the results of binomial logistic regressions with a desire for at least one additional child as the dependent variable and includes structural and financial incentives measures as well as individual and partner characteristics as the independent variables. The form of the binomial logistic model results in equation (5) if $J=1$. The table contains the marginal effects at the means of the independent variables, which can be interpreted as percent increase in the probability intending no more children with a one-unit increase in the independent variables. Both pseudo $R^{2}$ and the overall model fit measure $S$ are remarkably high at all parities. The structural and financial factors, however, do not appear to be powerful in their influence on a women's intention at all parities.

\subsection{Fertility Aspirations}

Next, we address the question of fertility aspirations under the implementation of certain public policies, including leave and work arrangements, childcare facilities, financial incentives, and infrastructure. As Table 1 shows, all the public policy measures were favoured by a vast majority of the women. The front-runner, on which over $90 \%$ of all women agreed, was flexible working hours for employed parents with small children and more and improved part-time work opportunities for parents with small children. Comprehensive tax relief for parents with underage children was the most popular of the financial public policy measures, as it garnered about $89 \%$ agreement. It is also interesting to note that the differences in the desired public policy measures reported are rather small among women at different parities.

Panel one of Table 6 reports the estimated mean causal effects of the implementation of structural and financial incentives measures on reproductive aspirations for women with and without children based on Kernel matching on the propensity score. For estimating the propensity scores we feed the set of covariates described in Section 3 (i.e. education, age, employment status, household income, etc.) in a probit model and estimated the probability of agreement to a specific policy measure. Since the substantive results of that estimation are not of primary interest for this paper, we refrained from reproducing the huge amount of tables (for each public policy measure and fertility aspiration a separate table). The overall 
Table 5: Effects of structural and financial factors on the probability of intending not to have any more children, logistic regressions (marginal effects) for parity 0,1 , and $2+$

\begin{tabular}{lcccc}
\hline \hline & All & Par. 0 & Par. 1 & Par. 2+ \\
\hline Enough childcare in neighbourhood & 0.077 & 0.114 & 0.007 & 0.014 \\
Household income: 1,022-1,605.9 EUR & -0.001 & 0.261 & -0.025 & -0.097 \\
Household income: 1,606-2,189.9 EUR & 0.001 & 0.235 & -0.074 & -0.033 \\
Household income: 2,190-3,211.9 EUR & 0.021 & -0.079 & -0.070 & -0.010 \\
Household income: 3,212+ EUR & 0.043 & 0.037 & 0.066 & 0.025 \\
Age 25-29 & 0.049 & 0.098 & -0.155 & 0.023 \\
Age 30-34 & $0.182^{* * *}$ & $0.385^{*}$ & -0.004 & 0.050 \\
Age 35-39 & $0.263^{* * *}$ & $0.626^{* *}$ & 0.211 & $0.078^{*}$ \\
Age 40-44 & $0.288^{* * *}$ & $0.811^{* * *}$ & 0.211 & $0.082^{*}$ \\
Age 45-49 & $0.298^{* * *}$ & $\mathrm{a})$ & $0.291^{*}$ & $0.084^{* *}$ \\
Married & $0.114^{*}$ & 0.037 & 0.018 & -0.032 \\
Seperated/Divorced & -0.074 & 0.005 & -0.281 & -0.222 \\
Widowed & $\mathrm{a})$ & $\mathrm{a})$ & $\mathrm{a})$ \\
Matura & $-0.027^{*}$ & -0.064 & 0.003 & -0.034 \\
Partner: Matura & $-0.172^{*}$ & -0.099 & $-0.306^{*}$ & $-0.101^{*}$ \\
Employed full-time & -0.054 & -0.045 & $0.213^{*}$ & -0.027 \\
Employed part-time & 0.088 & 0.003 & $0.289^{* *}$ & 0.030 \\
Partner: employed full-time & 0.055 & -0.044 & 0.178 & 0.011 \\
Catholic & 0.067 & -0.088 & 0.136 & $0.064^{*}$ \\
$5,000-49,999$ inhabitants & -0.026 & -0.192 & 0.153 & -0.032 \\
$50,000-999,999$ inhabitants & 0.067 & 0.187 & 0.141 & 0.019 \\
1,000,000+ inhabitants & $0.089^{*}$ & 0.103 & 0.174 & 0.004 \\
N & 608 & 190 & 120 & 281 \\
$S$ & 0.399 & 0.321 & 0.386 & 0.253 \\
\hline
\end{tabular}

Note: ${ }^{* * *} p \leq .001,{ }^{* *} p \leq .01,{ }^{*} p \leq .05$. a) Category predicts success perfectly. McFadden's pseudo $R^{2}=1-[\ln L(\alpha, \beta) / \ln L(\alpha)]$, where $\ln L(\alpha, \beta)$ is the $\log$-likelihood value of the full model and $\ln L(\alpha)$ is the $\log$-likelihood value of the constant only model. $S=\exp (\ln L(\alpha, \beta) / n)$ gives the average probability that the model generates the data. Source: PPA2 data, the author's own calculations. 
Table 6: Average effect of desired public policy measures on fertility aspirations, Kernel matching estimators based on the propensity score for all women, with and without children

\begin{tabular}{|c|c|c|c|c|}
\hline & (a) & (b) & (c) & $(d)$ \\
\hline \multicolumn{5}{|l|}{ All } \\
\hline$\overline{\text { (a) }}$ Maternity regulations & 0.133 & $0.147^{* * *}$ & $0.210^{* * *}$ & $0.167^{* * *}$ \\
\hline (i) Flexible working hours & 0.088 & $0.142^{* * *}$ & $0.193^{* * *}$ & $0.180 * * *$ \\
\hline (j) Part-time work & 0.139 & 0.070 & 0.091 & 0.079 \\
\hline (l) Leave for sick family member & 0.044 & $0.084^{*}$ & 0.065 & $0.079 *$ \\
\hline (c) Daycare up to age 3 & 0.040 & 0.055 & 0.072 & $0.108^{*}$ \\
\hline (d) Daycare ages 3-6 & 0.070 & $0.080^{*}$ & $0.164^{* * *}$ & $0.125^{*}$ \\
\hline (h) Daycare schoolchildren & 0.031 & $0.073^{*}$ & $0.074^{*}$ & 0.050 \\
\hline (k) Housing situation & $0.166^{* * *}$ & $0.141^{* * *}$ & $0.151^{* * *}$ & $0.147^{* * *}$ \\
\hline (b) Tax relief & 0.027 & 0.043 & 0.076 & 0.083 \\
\hline (e) Income dep. allowances & 0.024 & -0.015 & 0.043 & 0.039 \\
\hline (g) Family allowances & 0.090 & $0.127^{* * *}$ & $0.143^{* * *}$ & $0.129^{* * *}$ \\
\hline (f) Birth allowances & 0.020 & $0.066^{*}$ & $0.091^{*}$ & 0.063 \\
\hline (m) Allowances after leave & $0.111^{*}$ & $0.132^{* * *}$ & $0.157^{* * *}$ & $0.122^{* * *}$ \\
\hline \multicolumn{5}{|l|}{ Parity 0} \\
\hline (a) Maternity regulations & 0.240 & $0.241^{* * *}$ & 0.115 & 0.201 \\
\hline (i) Flexible working hours & -0.011 & 0.137 & 0.115 & $0.245^{*}$ \\
\hline (j) Part-time work & 0.152 & 0.101 & 0.128 & 0.121 \\
\hline (l) Leave for sick family member & 0.053 & 0.108 & 0.013 & 0.106 \\
\hline (c) Daycare up to age 3 & 0.033 & 0.009 & -0.003 & 0.068 \\
\hline (d) Daycare ages 3-6 & -0.027 & 0.117 & 0.130 & 0.097 \\
\hline (h) Daycare schoolchildren & 0.025 & 0.081 & 0.043 & -0.072 \\
\hline (k) Housing situation & $0.193^{*}$ & $0.142^{*}$ & $0.157^{*}$ & 0.095 \\
\hline (b) Tax relief & -0.042 & 0.031 & -0.072 & -0.076 \\
\hline (e) Income dep. allowances & 0.047 & 0.011 & 0.074 & 0.097 \\
\hline (g) Family allowances & 0.138 & $0.262^{* * *}$ & $0.183^{*}$ & 0.155 \\
\hline (f) Birth allowances & 0.005 & 0.044 & 0.071 & -0.005 \\
\hline (m) Allowances after leave & 0.036 & $0.190 * * *$ & $0.159^{*}$ & $0.165^{*}$ \\
\hline
\end{tabular}

Notes: (a) "It would be easier for me to have as many children as I wish." (b) "It would allow me to have my first/next child sooner." (c) "I would then think about having a(nother) child." (d) "I would then probably decide to have a(nother) child." ${ }^{* * *} p \leq .001,{ }^{* *} p \leq .01,{ }^{*} p \leq .05$. Source: PPA2 data, the author's own calculations.

model fit of the estimated propensity scores was high. ${ }^{7}$ Respondents with and without fertility aspirations were than matched on the estimated propensity scores according to the Kernel matching algorithm. The mean effect of a certain public policy measure is then the mean difference in the share of respondents having fertility aspirations who desire and do not desire a certain policy measure weighted by a weight based on the matching procedure.

The agreement with the "I would then think about having a(nother) child" statement (model c) could be considerably increased by improved maternity regulations for working women who have small children (about 21\%), by flexible working times for employed parents with small children (19\%), by better daycare facilities for children between three and six years of use (16\%), and by daycare facilities for children before and after school as well as during the school holidays (7\%). Also, financial incentives, such as a considerable increase on family allowances per child per month, higher birth allowances, as well as allowances to cover the gap between the expiration of parental leave allowances and the end of a spell of full-time childcare would have a strong positive causal effect on thinking about having a(nother) child.

The same financial incentives would increase the proportion of women who agree with

\footnotetext{
${ }^{7}$ The estimated coefficients for the propensity scores are available upon request from the author.
} 
the statement "It would allow me to have my first/next child sooner" (model b). Structural policy measures aimed at leave and work arrangements (flexible working hours, improved maternity regulations, leave for sick family members), childcare facilities for children three and above, and improved housing conditions could also significantly contribute to an increase in the proportion of women who would be able to have their first or next child sooner.

The agreement with the "I would then probably decide to have a(nother) child" statement (model d) could be considerably increased by almost exactly the same structural and financial policy measures. Additionally, better daycare facilities for children between three and six years of age could positively contribute to the decision to have a(nother) child.

Concerning the item "It would be easier for me to have as many children as I wish" (model a), we do not find any significant causal effects for either improved leave and work arrangements, childcare facilities, or financial incentives. Only an improved housing situation for families with small children could significantly increase the proportion of women who agree with the above statement. Summing up, according to our empirical analysis both structural and financial incentives have a causal effect on allowing to have the first/next child sooner, on thinking about having a(nother) child and on probably deciding to have a(nother) child, and to a lower extent on achievement of total fertility.

Panel two of Table 6 and Table 7 shows the parity dependence of these results. For parity zero women, improving the housing situation of families with small children would help them to have as many children as they wish (model a), to have their first child sooner (model b), and to think about having a first child at all (model c). In terms of financial policies, the increase of family allowances per child per month as well as additional allowances after the parental leave is over could improve the proportion of women who would have their child earlier, who would think about having another child, and who would probably decide to have a child at all.

This situation changes at higher parities. For women at parity one, more and improved possibilities of part-time work have an effect on the timing (model b), thinking (model c), and deciding (model d) about another child. Improved maternity regulations, and flexible working hours also have significant causal effects on the timing of additional childbearing. Flexible working hours are also an important causal factor in the decision to have a(nother) child. Concerning the financial policy measures, allowances to cover the time after expiration of the parental leave allowances is the only policy measure that has a causal effect on the different aspects of fertility aspirations.

At higher parities (parity 2 and more), a considerable increase of family allowances per child and month significantly contribute to the fertility aspirations. The structural policy measures seem to be more important to these women compared to women at parity one and zero. Improved maternity regulations, flexible working time, leave to care for sick family members, improved childcare at all ages, and improved housing conditions all have causal effects on thinking, deciding, and timing of further children.

\section{Discussion}

In this study, we examined the causal effects of structural and financial incentives and constraints on fertility preferences and intentions using data from the Austrian Population Policy Acceptance Survey 2001. In particular, we investigated their effects on (i) the desired total number of children, (ii) wanting not any versus not any additional children, and (iii) fertility aspirations under the implementation of certain policy measures.

The results of our analysis have demonstrated that structural constraints for children affect fertility preferences, that is the total desired number of children for all women regardless 
Table 7: Average effect of desired public policy measures on fertility aspirations, Kernel matching estimators based on the propensity score for parity 1 and $2+$

\begin{tabular}{lcccc}
\hline \hline & (a) & (b) & $(\mathrm{c})$ & $(\mathrm{d})$ \\
\hline Parity 1 & & & & \\
\hline (a) Maternity regulations & 0.393 & $0.385^{*}$ & 0.372 & 0.250 \\
(i) Flexible working hours & 0.015 & $0.262^{*}$ & 0.038 & $0.308^{*}$ \\
(j) Part-time work & 0.333 & $0.383^{* * *}$ & $0.379^{*}$ & $0.337^{* *}$ \\
(l) Leave for sick family member & -0.056 & 0.162 & 0.038 & 0.016 \\
(c) Daycare up to age 3 & 0.098 & -0.024 & 0.069 & 0.176 \\
(d) Daycare ages 3-6 & -0.053 & 0.266 & $0.408^{*}$ & 0.347 \\
(h) Daycare schoolchildren & -0.091 & -0.113 & -0.123 & -0.157 \\
(k) Housing situation & 0.283 & 0.234 & 0.233 & 0.287 \\
(b) Tax relief & -0.384 & -0.325 & -0.041 & -0.100 \\
(e) Income dep. allowances & -0.051 & -0.306 & -0.201 & -0.267 \\
(g) Family allowances & -0.181 & 0.118 & -0.020 & -0.012 \\
(f) Birth allowances & -0.059 & 0.153 & 0.200 & 0.133 \\
(m) Allowances after leave & $0.422^{*}$ & $0.297^{*}$ & $0.450^{* *}$ & $0.379^{*}$ \\
\hline Parity 2+ & & & & \\
(a) Maternity regulations & 0.131 & $0.110^{* *}$ & $0.168^{*}$ & 0.104 \\
(i) Flexible working hours & 0.121 & $0.128^{* * *}$ & $0.222^{* * *}$ & $0.128^{*}$ \\
(j) Part-time work & 0.216 & -0.010 & 0.070 & 0.033 \\
(l) Leave for sick family members & 0.032 & 0.059 & $0.117^{*}$ & $0.110^{*}$ \\
(c) Daycare up to age 3 & -0.022 & 0.064 & 0.098 & $0.133^{* *}$ \\
(d) Daycare ages 3-6 & 0.088 & 0.051 & $0.150^{* * *}$ & $0.107^{*}$ \\
(h) Daycare schoolchildren & 0.071 & $0.079^{*}$ & $0.113^{* *}$ & $0.103^{*}$ \\
(k) Housing situation & 0.047 & $0.108^{* * *}$ & $0.112^{*}$ & $0.106^{*}$ \\
(b) Tax relief & 0.010 & 0.034 & 0.057 & 0.109 \\
(e) Income dep. allowances & -0.014 & -0.005 & 0.042 & 0.034 \\
(g) Family allowances & $0.170^{*}$ & $0.082^{*}$ & $0.153^{* * *}$ & $0.130^{* * *}$ \\
(f) Birth allowances & 0.020 & 0.048 & 0.044 & 0.088 \\
(m) Allowances after leave & 0.092 & 0.050 & $0.167^{* * *}$ & 0.094 \\
\hline Notes (a) w woul be & & & & \\
\hline
\end{tabular}

Notes: (a) "It would be easier for me to have as many children as I wish." (b) "It would allow me to have my first/next child sooner." (c) "I would then think about having a(nother) child." (d) "I would then probably decide to have a(nother) child." ${ }^{* * *} p \leq .001,{ }^{* *} p \leq .01,{ }^{*} p \leq .05$. Source: PPA2 data, the author's own calculations. 
of parity. They also suggest that an increasing demand for structural measures at the macro level due to increasing female employment may explain at least part of the observed decreasing fertility preferences and fertility outcomes.

What is notable about our results is that Austrian women with and without children do not show the expected response on financial constraints in terms of an adjustment in the total desired number of children. This result is especially important since the Austrian government tries to increase fertility mainly through generous financial incentives. Structural measures aimed at reducing the incompatibility between childrearing and employment, however, are hardly discussed by the conservative Austrian government. However, we should be careful in formulating policy recommendations since our results are neither stable with respect to fertility intensions, that is wanting not any or not any additional children, nor with respect to fertility aspirations under the implementation of ceratin desired policy measures.

As far as the fertility aspirations of childless women are concerned, improvements to the housing situation and post-parental leave allowances significantly contribute to the fertility aspirations, including thinking about, deciding on, and timing the arrival of a first child. For women at parity one, structural incentives affecting work arrangements (in particular flexible working hours and the availability of part-time work) as well as allowances to cover the time after expiry of the parental leave allowances have a clear positive effect on fertility aspirations. At higher parities, a considerable increase of family allowances per child per month positively could contribute to increase fertility aspirations.

Although we applied the latest statistical techniques for estimating causal effects, the robustness of the findings in this paper could be questioned. In trying to get to the bottom of our research question, we have to admit that the estimated causal effects may be biased due to omitted variables in the different models since the choice of covariates influence the propensity scores. For instance, the fertility preferences and intentions of the partner or spouse cannot be controlled for in the empirical analysis due to unavailability of data (cf. Thomson et al. 1990; Thomson 1997; van Peer 2002; Heiland and Prskawetz 2004). Furthermore, the models for the desired number of children and for wanting more children control for important individual and partner characteristics, such as education and employment, but do not, for example, include the sex composition of the previous children. Miller and Pasta (1995) provide evidence from U.S. data that the sex of the present children affects the desired total number of children. The same holds true for our modelling of the propensity scores for estimating the effect of various incentives on fertility aspirations. Thus, our results should not be interpreted as 'true' causal effects (which could be researched only with an randomised experiment, real policy measures and actual achieved fertility) but more as an indication on the direction and strength of the causal influence of structural and financial incentives and constraints on fertility preferences, intentions, and aspirations.

\section{References}

Ajzen, Icek (1985) From Intentions to Actions: A Theory of Planned Behaviour. In J. Kuhl and J. Beckman (eds.), Action Control: From Cognition to Behaviour. New York: Springer, 11-39.

Ajzen, Icek and Martin Fishbein (1980) Understanding Attitudes and Predicting Behaviour. Engelwood Cliffs, NJ: Prentice Hall.

Becker, Gary S. (1991) A Treatise on the Family, enl. ed. Cambridge, Mass.: Harvard University Press.

Becker, Gary S. and H. Gregg Lewis (1973) On the Interaction between the Quantity and Quality of Children. Journal of Political Economy 81: S279-S288. 
Becker, Sascha O. and Ichino, Andrea (2002) Estimation of Average Treatment Effects Based on Propensity Scores. The Stata Journal 2: 358-377.

Bongaarts, John (1990) The Measurement of Wanted Fertility. Population and Development Review 16: $487-506$.

Bongaarts, John (2001) Fertility and Reproductive Preferences in Post-Transitional Societies. Population and Development Review 27 (Supplement): 260-281.

Bongaarts, John (2002) The End of Fertility Transition in the Developed World. Population and Development Review 28: 419-444.

DaVanzo, Julie, Christine E. Peterson, and Nathan R. Jones (2003) How Well Do Desired Fertility Measures for Wives and Husbands Predict Subsequent Fertility? Labor and Population Program Working Paper Series 03-16, RAND.

Dawid, A.P. (1979) Conditional Independence in Statistical Theory. Journal of the Royal Statistical Society, Series B 41: 1-31.

Frejka, Tomas, and Jean-Paul Sardon (2003) Fertility in Austria: Past, Present and the Near Future. Working Papers 02/2003. Vienna Institute of Demography.

Gangl, Markus and Thomas A. DiPrete (2004) Kausalanalysen durch Matchingverfahren. DIW Discussion Paper 401. Berlin: German Institute for Economic Research.

Gauthier, Anne H. (2002) Family Policies in Industrialized Countries: Is there Convergence? Population 57: $447-474$.

Gisser, Richard (ed.) (2003) Familie, Geschlechterverhältnis, Alter und Migration: Wissen, Einstellungen und Wünsche der Österreicherinnen und Österreicher. Research Report No. 25, Vienna Institute of Demography.

Goldstein, Joushua R., Wolfgang Lutz, and Maria Rita Testa (2003) The Emergence of Sub-Replacement Family Size Ideals in Europe. Population Research and Policy Review 22: 479-496.

Greene, William H. (2003) Econometric Analysis, 5th ed. Englewood Cliffs, N.J.: Prentice Hall.

Heckman, James J., V. Joseph Hotz, and James R. Walker (1985) New Evidence on the Timing and Spacing of Births. American Economic Review 75: 179-184.

Heckman, James, J., Hidehiko Ichomura, and Petra E. Todd (1998) Matching as an Econometric Evaluation Estimator. Review of Economic Studies 65: 261-294.

Hanika, Alexander (2003) Volkszählung 2001: Paritäts-Fertilitätstafeln. Statistische Nachrichten 2/2003: 90-96.

Heckman, James J. and James R. Walker (1990) The Relationship Between Wages and Income and the Timing and Spacing of Births: Evidence from Swedish Longitudinal Data. Econometrica 58: 14111441.

Heiland, Frank and Alexia Prskawetz (2003) A Multivariate Analysis of Desired and Excess Desired Family Size in West Germany. Unpublished manuscript, Florida State University.

Hoem, Jan M., Alexia Prskawetz, and Gerda Neyer (2001) Autonomy or Conservative Adjustment? The Effect of Public Policies and Educational Attainment on Third Births in Austria, 1975-96. Population Studies 55: 249-261.

Hotz, Joseph V., Jacob A. Klerman, and Robert J. Willis. (1997) The Economics of Fertility in Developed Countries. In Mark R. Rosenzweig and Oded Stark (eds.), Handbook of Population and Family Economics. Amsterdam: Elsevier, 275-347.

Kohler, Hans-Peter (2001) Fertility and Social Interaction: An Economic Perspective. New York: Oxford University Press. 
Lee, Ronald (1980) Aiming at a Moving Target: Period Fertility and Changing Reproductive Goals. Population Studies 34: 205-226.

Lesthaege, Ron and Johan Surkyn (1988) Cultural Dynamics and Economic Theories of Fertility Change. Population and Development Review 14: 1-45.

Miller, Warren B. and David J. Pasta (1995) How does Childbearing Affect Fertility Motivations and Desires? Social Biology 42: 185-198.

Morgan, S. Philip (1981) Intention and Uncertainty at Later Stages of Childbearing: The United States, 1956 to 1970. Demography 18: 267-285.

Morgan, S. Philip (1982) Parity-specific Fertility Intentions and Uncertainty: The United States, 1970 to 1976. Demography 19: 215-334.

Morgan, S. Philip (2003) Is low Fertility a Twenty-First-Century Crises? Demography 40: 589-603.

Moors, Hein and Rossella Palomba (eds.) (1995) Population, Family and Welfare. A Comparative Study of European Attitudes, Vol. I. Oxford: Clarendon Press.

Namboodiri, Krishnan (1983) Sequential Fertility Decision Making and the Life Course. In Rodolfo A. Bulatao and Ronald D. Lee (eds.), Determinants of Fertility in Developing Countries, Vol. 2. New York: Academic Press, 444-472.

National Research Council (2001) Diffusion Processes and Fertility Transition: Selected Perspectives. Edited by John B. Casterline. Washington, D.C.: National Academy Press.

Noack, Turid and Lars Østby (2002) Free to Choose - But Unable to Stick to it? Norwegian Fertility Expectations and Subsequent Behaviour in the Following 20 Years. In Eric Klijzing and Martine Corijn (eds.), Fertility and Partnerships in Europe: Findings and Lessons from Comparative Research, Vol. 2. Geneva: United Nations, 103-116.

O'Donoghue, Cathal and Holly Sutherland (1999) Accounting for the Family in European Income Tax Systems. Cambridge Journal of Economics 23: 565-598.

OECD (2001) Balancing Work and Family Life: Helping Parents into Paid Employment. In Employment Outlook. Paris: Organization for Economic Cooperation and Development, 129-166.

Pritchett, Lant H. (1994) Desired Fertility and the Impact of Population Policies. Population and Development Review 20: 1-55.

Quesnel-Vallée, Amélie and S. Philip Morgan (2003) Missing the Target? Correspondence of Fertility Intentions and Behavior in the U.S. Population Research and Policy Review 22: 497-525.

Rindfuss, Ronald R., S. Philip Morgan, and Gray Swicegood (1988) First Births in America: Changes in the Timing of Parenthood. Berkeley: University of California Press.

Rosenbaum, Paul T. and Donald B. Rubin (1983) The Central Role of Propensity Score in Observational Studies. Biometrika 70: 41-55.

Rubin, Donald B. and Neal Thomas (1996) Matching Using Estimated Propensity Scores: Relating Theory to Practice. Biometrics 52: 249-261.

Ryder, Norman B. (1980) Components of Temporal Variations in American Fertility. In Robert W. Hiorns (ed.), Demographic Patterns in Developed Societies. London: Taylor \& Francis, 15-54.

Schoen, Robert, Nan M. Astone, Young J. Kim, Constance A. Nathanson, and Jason M. Fields (1999) Do Fertility Intentions Affect Fertility Behavior? Journal of Marriage and the Family 61: 790-799.

Smith, Herbert L. (1997) Matching with Multiple Controls to Estimate Treatment Effects in Observational Studies. Sociological Methodology 27: 325-353.

Symeonidou, Haris (2000) Expected and Actual Family Size in Greece. European Journal of Population 16: 335-352. 
Thomson, Elizabeth (1997) Couple Childbearing Desires, Intentions, and Births. Demography 34: 343-354.

Thomson, Elizabeth, Elaine E. McDonald, and Larry L. Bumpass (1990) Fertility Desires and Fertility: Hers, His, and Theirs. Demography 27: 579-588.

Van de Kaa, Dirk J. (2001) Postmodern Fertility Preferences: From Changing Value Orientation to New Behaviour. Population and Development Review 27 (Supplement): 290-331.

Van Peer, Christine (2002) Desired and Realized Fertility in Selected FFS-Countries. In Miroslav Macura and Gijs Beets (eds.), Dynamics of Fertility and Partnership in Europe: Insights and Lessons from Comparative Research, Vol. 1. New York: United Nations, 117-142.

Willis, Robert J. (1973) A New Approach to the Economic Theory of Fertility Behavior. Journal of Political Economy 81: S14-S64.

Winkelmann, Rainer (2003) Econometric Analysis of Count Data. Heidelberg: Springer. 